Research Article

\title{
Optimization of Networked Governance Models Using Complex System Governance Concepts in Sports Services
}

\author{
Yuhua Gao ${ }^{D},{ }^{1}$ Xinxi Zhen, ${ }^{1}$ and Yan Xiong ${ }^{2}$ \\ ${ }^{1}$ Guangzhou Sports University, Guangzhou, Guangdong, China \\ ${ }^{2}$ College of P.E. \& Sports Science, Guangzhou University, Guangzhou, Guangdong, China
}

Correspondence should be addressed to Yuhua Gao; 11071@gzsport.edu.cn

Received 8 October 2021; Revised 28 October 2021; Accepted 24 November 2021; Published 22 December 2021

Academic Editor: Zhihan Lv

Copyright (c) 2021 Yuhua Gao et al. This is an open access article distributed under the Creative Commons Attribution License, which permits unrestricted use, distribution, and reproduction in any medium, provided the original work is properly cited.

In order to increase the participation rate of community residents in sports services, on the governance concept of a complex system, the networked governance model under sports services has been studied. Firstly, by introducing the background of networked governance, the supply of sports services is selected as the research object. The selected sports service providers are the government, universities, enterprises, associations, and residents. Secondly, the structural model of sports service supply has been constructed. Combining the direct effects model and the intermediary relationship model, the questionnaire is designed. The current situation of sports service supply in the study area is analyzed. Finally, on this basis, the networked governance model strategy has been optimized. The results show that because the age distribution of the subjects is relatively young, the residents in the study area have a higher degree of understanding of sports services. In the direct relationship model and the mediating effect model, the 6 fitting indicators are consistent with the standard values, and no abnormal data appeared. The government, universities, and associations have a significant influence on the supply of sports services. The impact of enterprises and residents on the supply of sports services is not significant. The community environment plays an intermediary role in the supply of residents and sports services, and the supply of enterprises and sports services. Network governance should pay more attention to the participation of multiple subjects, change the leading role of the government, break down the communication barriers between supply subjects, establish an information security mechanism, and build an information sharing system. The research results provide a reference direction for the development of network management in sports services.

\section{Introduction}

Sports services refer to people who have certain professional knowledge, skills, and experience in sports. These people can be engaged in the production of sports services [1]. And they carry out purposeful activities to produce the special use value of this sports service $[2,3]$. With the acceleration of urbanization, the living functions of urban communities have become the core of community construction [4], and the construction of healthy urban communities is closely related to the rationality of the layout of sports service resources $[5,6]$. China's current development requirements are to modernize the country's governance capabilities and realize the country's governance system. Since the twentyfirst century, Internet technology has developed rapidly, and networked governance can integrate and mobilize social multiresources through public entities and existing public interest needs to deal with complex social situations $[7,8]$.

The United States is the first to research on sports public services. In 2010, the US government clearly proposed to improve the physical fitness of residents [9]. The United Kingdom, Germany, Japan, and Australia have also promulgated related bills and made certain rules and regulations for sports services $[10,11]$. China's research on networked governance is on meeting China's actual needs, so it has certain Chinese applicability [12, 13]. For example, researchers used a widely defined network-based framework to track the evolution of urban renewal decisions in Guangzhou, China, and learned from the concept of network governance to obtain China's ever-developing urban 
regeneration policies and a broader governance network in urban regeneration practices [14]. Network governance goes beyond grid governance and gives market management more vitality [15].

At this stage, the participation rate of residents in community sports services is low in China. Therefore, the research combines the concept of complex system governance to conduct in-depth exploration on the supply of community sports services. The purpose is to solve the problems exposed in sports services at this stage and implement a sports service network model that is more in line with the current urban development in China. The innovative point lies in the integration of networked governance into the supply of community sports services, combining the different levels of networked governance with the characteristics of the supply of community sports services, and proposed existing targeted networked governance measures. The research has made a certain contribution to promoting national governance capacity and governance system, innovation, and strengthening the construction of social governance system.

\section{Research Method of Optimizing Networked Governance Model}

The community sports service in a province of China is selected as the research object. Since community services are mainly public services, the research is mainly about the optimization of networked governance models under sports public services. Firstly, the research introduces the background. Secondly, it analyses the status quo of sports services in the study area by taking the supply relationship of sports services as the breakthrough point. Finally, on this basis, optimization measures are proposed for networked governance.

\subsection{Implementation of Sports Service Supply Structure Model.} The supply subjects of the study area are divided into five categories, including government, universities, enterprises, community residents, and associations, as variables in the sports service supply model, shown in Figure 1.

Figure 1 shows that among these five main bodies, the government plays a guiding and supporting role. The enterprise also has advantages in sports services, and the business principles of the enterprise require the enterprise to continuously iterate its products and services. As the main body of providing social services and transporting talents to the society, colleges and universities radiate intelligence and human resources to the surrounding communities. As a participant of the main body of supply, the association is an innovative measure to improve the way of sports service [16]. As the main body of supply, community residents are also demanders of sports services [17].

The specific content of the community environment is shown in Figure 2.

Figure 2 shows that among the three main parts of the community environment, the community political environment refers to the interactive relationship between the state and the community, and the relationship between the democratization of community politics and political construction. The process of community residents' participation in decision-making is mainly reflected in the expectations of managers for their own roles [18]. The community development environment is the overall level of community development and innovation. The community service environment includes medical and health, cultural propaganda, traffic environment, etc. [19].

Sports service supply is an important part of China's social system and social structure. The elements of sports service supply include sports service infrastructure and service scale to meet the needs of physical exercise, the sports service management system is perfect and the supply organization is set up reasonable, and the sports service supply capacity is on the rise $[20,21]$.

The research sets 5 direct hypotheses and 11 indirect hypotheses, as shown in Table 1 .

Table 1 shows that the direct hypothesis here is mainly the hypothesis of the relationship between the supply of sports services and the five supply entities. The indirect hypothesis is mainly the hypothesis of the relationship between the five supply entities and the community environment, as well as the community environment and sports supply.

Implement a conceptual model of the influence relationship and path between the main body of sports service and service supply, as shown in Figure 3.

The basic structure in Figure 3 is used to analyze the path of influence between the supply of sports services and the main body of the service. The conceptual model is verified by a questionnaire, and the results of the questionnaire will provide theoretical support for the sports service supply model.

The questionnaire set up is divided into four parts, including the basic information of the respondent, the main elements of the surveyor's provision of sports services (18 test questions), the community environment (8 test questions), and the sports service degree of approval (3 test questions). The evaluation adopts the 5-level scoring method of the Likert scale [22], with 1-5 indicators, which represent "very disagree," "disagree," "general," "agree," and "very agree," respectively. 209 questionnaires were distributed, and 193 valid questionnaires were recovered, with an effective rate of $92.3 \%$. The questionnaire distribution method is a combination of online and offline. Analysis of Moment Structure 21.0 and Statistical Product and Service Solutions 26.0 data analysis tools are adopted here.

The specific items of the questionnaire are shown in Table 2.

In the descriptive analysis of the questionnaire, basic information includes gender, age, education level, occupation, and average monthly income. Among them, the age is divided into 18 years old, 18-35 years old, 36-45 years old, 46-60 years old, and 60 years old and above; education level is divided into junior high school and below, high school or college, undergraduate, master, and doctor and above; occupations are divided into civil servants and public institutions, corporate personnel, freelancers, retirees, and 


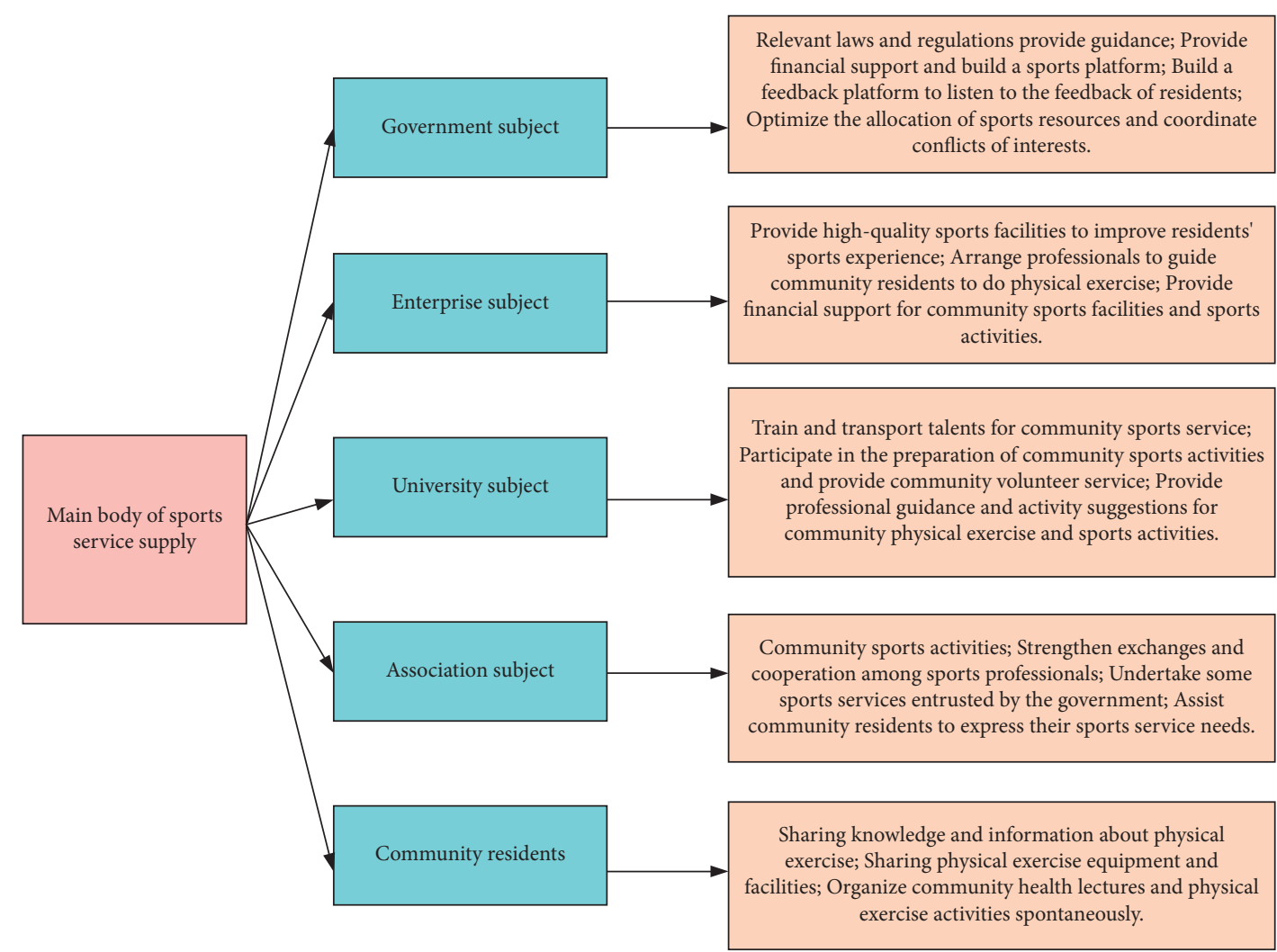

Figure 1: The main supply body of sports service.

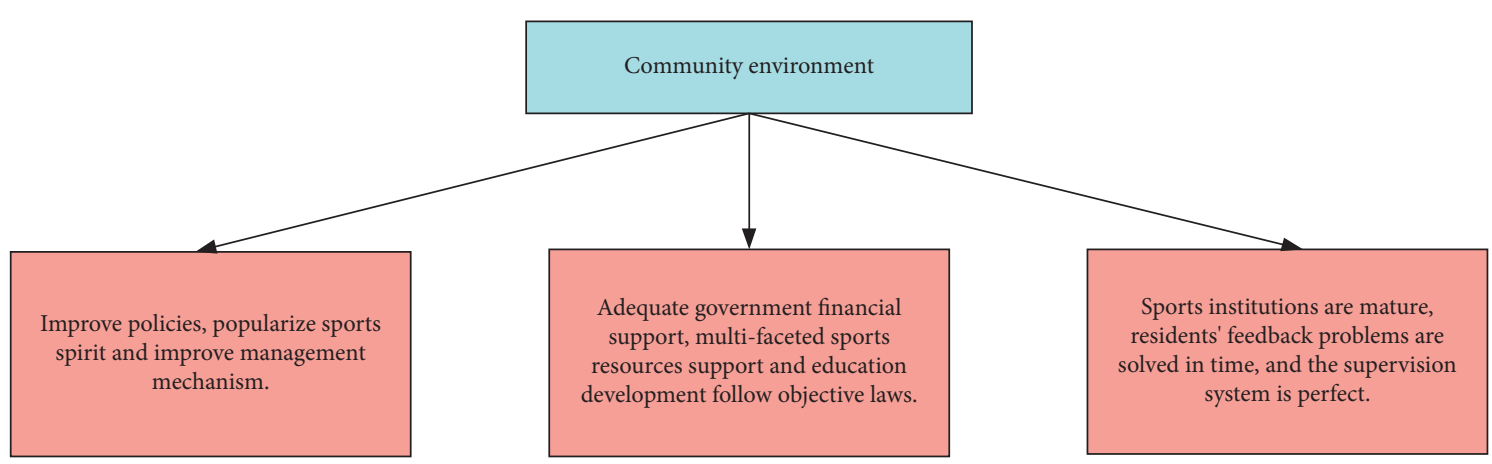

FIgURE 2: The elements of the community environment.

others; the average monthly income is divided into 3000 yuan or less, 3000-5000 yuan, 5001-8000 yuan, 8001-10000 yuan, and 10000 yuan or more. $1-5$ represent 5 divided areas.

The reliability test of the scale is carried out by Cronbach's $\alpha$ [23]. If the value of $\alpha$ is less than or equal to 0.7 , the internal consistency of the scale is unacceptable. The calculation of Cronbach's $\alpha$ is expressed as

$$
\alpha=\left(\frac{k}{k-1}\right) \cdot\left(1-\frac{\sum S_{i}^{2}}{S_{T}^{2}}\right) .
$$

In Eq. (1), $k$ is the number of question items of the survey target, $S_{i}^{2}$ is the variance of the $i$-th question of all respondents, and $S_{T}^{2}$ is the variance of the sum of the answers to all the question items. Among them, the calculation of variance $S_{T}^{2}$ is as follows:

$$
S_{T}^{2}=\frac{\sum(T-\mu)^{2}}{N}
$$

In Eq. (2), $T$ is the variable, $\mu$ is the overall mean, and $N$ is the number of overall cases.

The evaluation of the reliability of a single index uses Corrected Item-Total Correlation (CITC) and the revised item [24]. The definition of CITC is shown as follows:

$$
\nu(I, J)=\frac{\operatorname{Cov}(I, J)}{\sqrt{\operatorname{var}[I] \operatorname{var}[J]}} .
$$


TABLE 1: Research hypothesis.

\begin{tabular}{|c|c|c|}
\hline Hypothetical type & $\begin{array}{l}\text { Hypothetical } \\
\text { number }\end{array}$ & The specific content of the hypothesis \\
\hline \multirow{5}{*}{ Direct hypotheses } & Sla & Sports services are significantly affected by government entities \\
\hline & $\mathrm{S} 2 \mathrm{a}$ & Sports services are significantly affected by the main body of the enterprise \\
\hline & S3a & Sports services are significantly affected by the main body of colleges and universities \\
\hline & S4a & Sports services are significantly affected by the main body of the association \\
\hline & S5a & Sports services are significantly affected by residents \\
\hline \multirow{11}{*}{$\begin{array}{l}\text { Indirect } \\
\text { hypotheses }\end{array}$} & S1b & The community environment is significantly affected by the government \\
\hline & $\mathrm{S} 2 \mathrm{~b}$ & The community environment is significantly affected by business entities \\
\hline & $\mathrm{S} 3 \mathrm{~b}$ & The community environment is significantly affected by the main body of the university \\
\hline & $\mathrm{S} 4 \mathrm{~b}$ & The community environment is significantly affected by the main body of the association \\
\hline & S5b & The community environment is significantly affected by the residents \\
\hline & S6 & Sports services are significantly affected by the community environment \\
\hline & S6a & $\begin{array}{c}\text { The community environment plays an intermediary role between sports services and the supply of } \\
\text { government entities }\end{array}$ \\
\hline & S6b & $\begin{array}{l}\text { The community environment plays an intermediary role between the sports service and the supply } \\
\text { of the main body of the enterprise }\end{array}$ \\
\hline & S6c & $\begin{array}{l}\text { The community environment plays an intermediary role between sports services and the supply of } \\
\text { the main body of colleges and universities }\end{array}$ \\
\hline & S6d & $\begin{array}{l}\text { The community environment plays an intermediary role between the sports service and the supply } \\
\text { of the main body of the association }\end{array}$ \\
\hline & S6e & $\begin{array}{c}\text { The community environment plays an intermediary role between sports services and the supply of } \\
\text { residents }\end{array}$ \\
\hline
\end{tabular}

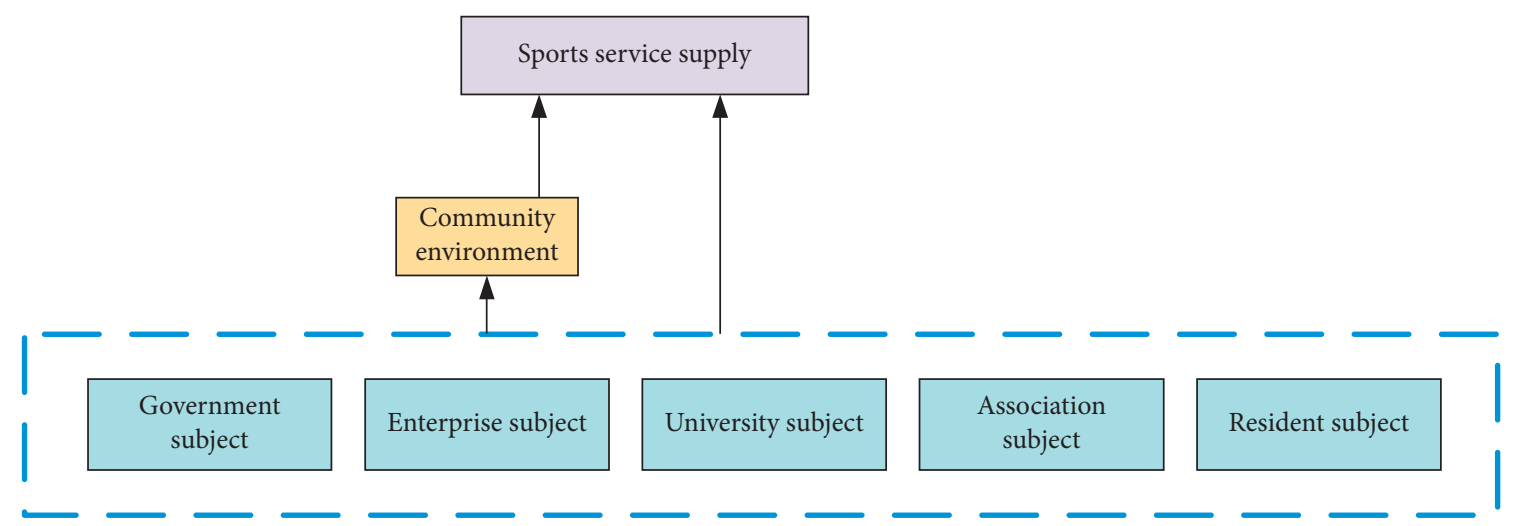

FIGURE 3: Supply conceptual model of sports service.

In equation (3), $\operatorname{Cov}(I, J)$ is the covariance and var refers to the variance, which must be greater than 0.5 . When the CITC value and $\alpha$ value of the observed variable and the latent variable do not meet the requirements, they need to be revised or deleted [25]. Reliability analysis includes the analysis of the supplier, the community environment, and the supply of sports services.

The validity analysis is carried out from the aspect of construct validity [26]. Kaiser-Meyer-Olkin (KMO) and Bartlett sphere test are used to determine whether the questionnaire data can be used for factor analysis. The specific equations of $\mathrm{KMO}$ and Bartlett sphere test are expressed as (4)-(6).

$$
K M O=\frac{\mathrm{BB}}{\mathrm{AA}+\mathrm{BB}} .
$$

In equation (4), $\mathrm{AA}$ is the sum of squares of the partial correlation coefficients between the two in all variables and
$\mathrm{BB}$ is the sum of squares of the correlation coefficients between the two in all variables. When $\mathrm{KMO}$ value $>0.8$, the data is good.

$$
\begin{aligned}
X^{2} & =-\left(n-\frac{2 p+11}{6}\right) \ln |R|, \\
\mathrm{df} & =\frac{p(p-1)}{2} .
\end{aligned}
$$

Equations (5) and (6) are the calculation process of the statistics in the Bartlett test of sphericity. Among them, $n$ is the number of data records, $p$ is the number of variables in the factor analysis, and $|R|$ is the determinant of the correlation coefficient matrix $R$ value.

The average variance extraction method (AVE) and the topic factor loading coefficient method are used to measure the convergence validity of the questionnaire data [27], and the specific expressions are shown in equations (7) and (8). 
TABLE 2: Questionnaire specific items.

\begin{tabular}{|c|c|c|}
\hline Latent variable & $\begin{array}{c}\text { Index } \\
\text { number }\end{array}$ & The specific content of the topic \\
\hline \multirow{4}{*}{ Government entities } & $\mathrm{Z} 1$ & Policy guidance such as laws and regulations \\
\hline & $\mathrm{Z} 2$ & Financial support \\
\hline & $\mathrm{Z3}$ & Build a feedback platform \\
\hline & $\mathrm{Z} 4$ & Optimize resource allocation and coordinate conflicts \\
\hline \multirow{4}{*}{$\begin{array}{l}\text { The main body of colleges and } \\
\text { universities }\end{array}$} & G1 & Provide voluntary services for sports services \\
\hline & G2 & Provide venue and facility support \\
\hline & G3 & Provide professional guidance \\
\hline & G4 & Carry out diverse exchanges \\
\hline \multirow{3}{*}{ The main body of the enterprise } & Q1 & Provide high-quality facilities \\
\hline & Q2 & Arrange professional guidance \\
\hline & Q3 & Provide financial support \\
\hline \multirow{4}{*}{ The main body of the association } & $\mathrm{X} 1$ & Carry out several sports exchange activities \\
\hline & $\mathrm{X} 2$ & Communicate with professionals in sports \\
\hline & $\mathrm{X} 3$ & Undertake government-entrusted sports activities \\
\hline & $\mathrm{X} 4$ & Assist in responding to the needs of the masses \\
\hline \multirow{3}{*}{ Residents } & $\mathrm{J} 1$ & Physical exercise information and knowledge sharing \\
\hline & $\mathrm{J} 2$ & Facilities and equipment sharing \\
\hline & $\mathrm{J} 3$ & Spontaneous organization of sports activities \\
\hline \multirow{8}{*}{ The community environment } & $\mathrm{H} 1$ & Improve laws and regulations and popularize sportsmanship \\
\hline & $\mathrm{H} 2$ & Improve management service mechanism \\
\hline & $\mathrm{H} 3$ & The government provides sufficient financial support \\
\hline & $\mathrm{H} 4$ & Obtain multiple sports resources \\
\hline & H5 & Possesses the potential for sports development \\
\hline & H6 & Sports service agencies are mature \\
\hline & $\mathrm{H} 7$ & Residents can get timely feedback on problems \\
\hline & $\mathrm{H} 8$ & Improve the supervision system \\
\hline \multirow{3}{*}{ Sports service supply } & $\mathrm{T} 1$ & Physical exercise needs can be met by infrastructure and sports services \\
\hline & $\mathrm{T} 2$ & The supply of sports products is on the rise \\
\hline & $\mathrm{T} 3$ & $\begin{array}{l}\text { The sports service management system is perfect, and the supply organization is set } \\
\text { up reasonably }\end{array}$ \\
\hline
\end{tabular}

$$
\begin{aligned}
\operatorname{AVE} & =\frac{\sum_{i=1}^{n} L i^{2}}{n}, \\
A & =\left(\sqrt{\lambda_{1} \eta_{1}}, \sqrt{\lambda_{2} \eta_{2}}, \cdots, \sqrt{\lambda_{m} \eta_{m}}\right) .
\end{aligned}
$$

Equation (7) is the calculation equation of the average extraction variance method. Among them, $L i^{2}$ is the variance and $n$ is the number of terms. In equation (8), $\lambda$ is the eigenvalue of the correlation coefficient, $\eta$ is the corresponding normalized eigenvector, and $m$ is the number of terms. For items that require high factor loading in the measurement model, the average extraction variance should be no less than 0.5 , and the combined reliability of the latent variables should be no less than 0.7 . Finally, the discriminative validity analysis is performed, and the correlation coefficient between the square root factors of the average extracted variance value is used to evaluate the relationship [28]. Both the construct validity and the convergence validity are greater than 0.5 , indicating that the validity is good.

After the direct relationship model and the intermediary relationship model are implemented, they are evaluated. The evaluation method uses the fit of the model to check whether the fit index meets the requirements and obtain the result of the model path verification. Model testing also includes Bootstrap mediation effect testing, which mainly tests the influence relationship between the outcome variable and the antecedent variable $[29,30]$. The model fitting index and the core calculation equation in Bootstrap are shown in equations (9) and (10).

$$
X^{2}=\sum_{i=1}^{k} \frac{\left(O_{i}-T_{i}\right)^{2}}{T_{i}} .
$$

In equation (9), $k$ is the number of groups, $O$ is the observation frequency, and $T$ is the theoretical frequency.

$$
\bar{X}-t \frac{s}{\sqrt{n}}<\mu<\bar{X}+t \frac{s}{\sqrt{n}} \text {. }
$$

Equation (10) is the calculation of the confidence interval in the Bootstrap intermediary effect test. Among them, $t$ is the degree of freedom, $s$ is the number of observations, and $\bar{X}$ is the mean.

2.2. The Theoretical Background of Networked Governance. The core of network governance is the equal participation of multiple subjects. Government departments, enterprises, associations, and other entities should coordinately develop and jointly assume the responsibilities as the main body of supply. The government's responsibility in network governance is to organize resources, allocate public resources rationally, and maximize public value through the role of the 
relationship network of multiple subjects. Enterprises must follow the principles of market-oriented and profit-driven principles and ultimately achieve a win-win result of multiagent cooperation. Social organizations should strengthen their own social role and undertake the main body of sports services. The subjects of network governance can be divided into behavioral interaction and organizational relationships. As the core of network governance, the government is mainly responsible for promoting the realization of sports service goals and building networks from the perspective of organizational relationships. From the perspective of behavioral interaction, networked governance has changed the traditional mode of government work, making the horizontal connection between the government and social organizations and enterprises closer.

Information security mechanisms and effective communication are the two cores that make networked governance work. The information security mechanism requires that the major subjects be guided by common interests, timely understand the goals and trends of other subjects, strengthen information communication, and jointly coordinate resources. The effective communication mechanism is using the embedded network environment, which ensures the benign communication between the subjects and the efficiency of the coordination and interaction process.

The governance tools used in networked governance are no longer traditional norms and compulsory methods, but methods such as calling, mechanism design, etc., integrating economic and administrative methods into the field of sports service governance. The guiding ideology of networked governance of sports service supply in the study area includes "people-oriented," multisubject coordination, and networked governance.

\section{Analysis on the Research Results of Sports Service}

3.1. Basic Information Descriptive Statistical Results. The proportion of male and female in this survey is shown in Table 3.

Table 3 shows that among the 193 people who participated in the survey this time, 95 are females, accounting for $49.22 \%$, and 98 are males, accounting for $50.78 \%$. The number of males is slightly higher than the number of females, but the ratio of males to females is basically the same. In the number of participants in this survey, gender has no influence on the problems of this research.

The specific distribution of age, education level, occupation, and average monthly income is shown in Figure 4.

In Figure 4, the age distribution of the survey subjects is mainly concentrated in the 18 - to 35 -year-old population, and the proportion of the number of people in this range is 36.52. The 36- to 45-year-old population accounts for $32.08 \%$. In the education level survey, the proportion of people with a high school or junior college degree is the highest. In the occupational survey, the highest proportion is enterprise personnel, that is, the number of people with an average monthly income in the range of 3000-5000 yuan has
TABLE 3: Gender ratio.

\begin{tabular}{lcc}
\hline Options & Number (person) & Proportion (\%) \\
\hline Female & 95 & 49.22 \\
Male & 98 & 50.78 \\
Total & 193 & 100.00 \\
\hline
\end{tabular}

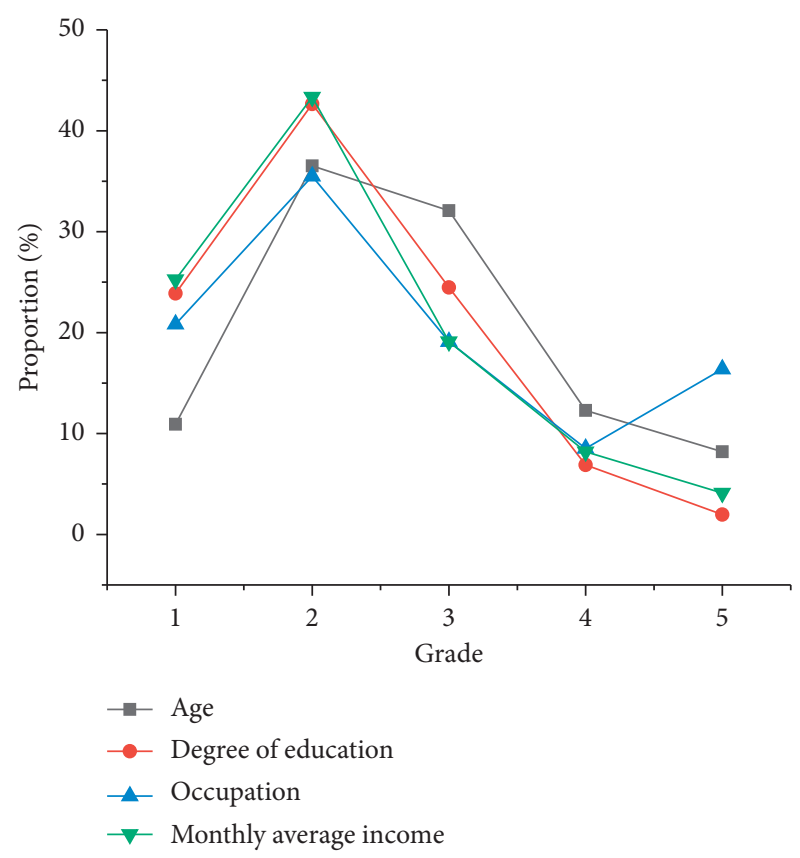

FIgURE 4: Basic information distribution.

the highest proportion. The main ages of residents in the research area are 18-45 years. The education level is mainly high school or junior college, the occupation is enterprise personnel, and the average monthly income is 3000-4000 yuan. Due to the relatively young age distribution, residents in the research area have a higher degree of understanding of sports services.

3.2. Structural Model Analysis. Combining the previous content, it is concluded that the reliability of the scale is $0.85>0.7$, the reliability of the latent variable combination is $0.8>0.7$, and the $\mathrm{KMO}$ value is $0.9>0.8$, indicating that the scale data is good. The construct validity is $0.58>0.5$, the convergence validity is $0.61>0.5$, and the reliability and validity results are all good. Therefore, the structural model can be used.

A direct relationship model is constructed between the main body of the community environment supply and the supply of sports services, as shown in Figure 5.

Figure 5 shows that, in the direct relationship structure model, five supply entities influence each other, and the five supply entities contain a total of 18 elements. Among them, the main body of the government is that with the widest radiation, which directly affects the main body of enterprises, universities, associations, and residents. The content of Figure 5 has yet to be verified. The content of Figure 5 will be evaluated later, and the nonconforming parts will be eliminated. 


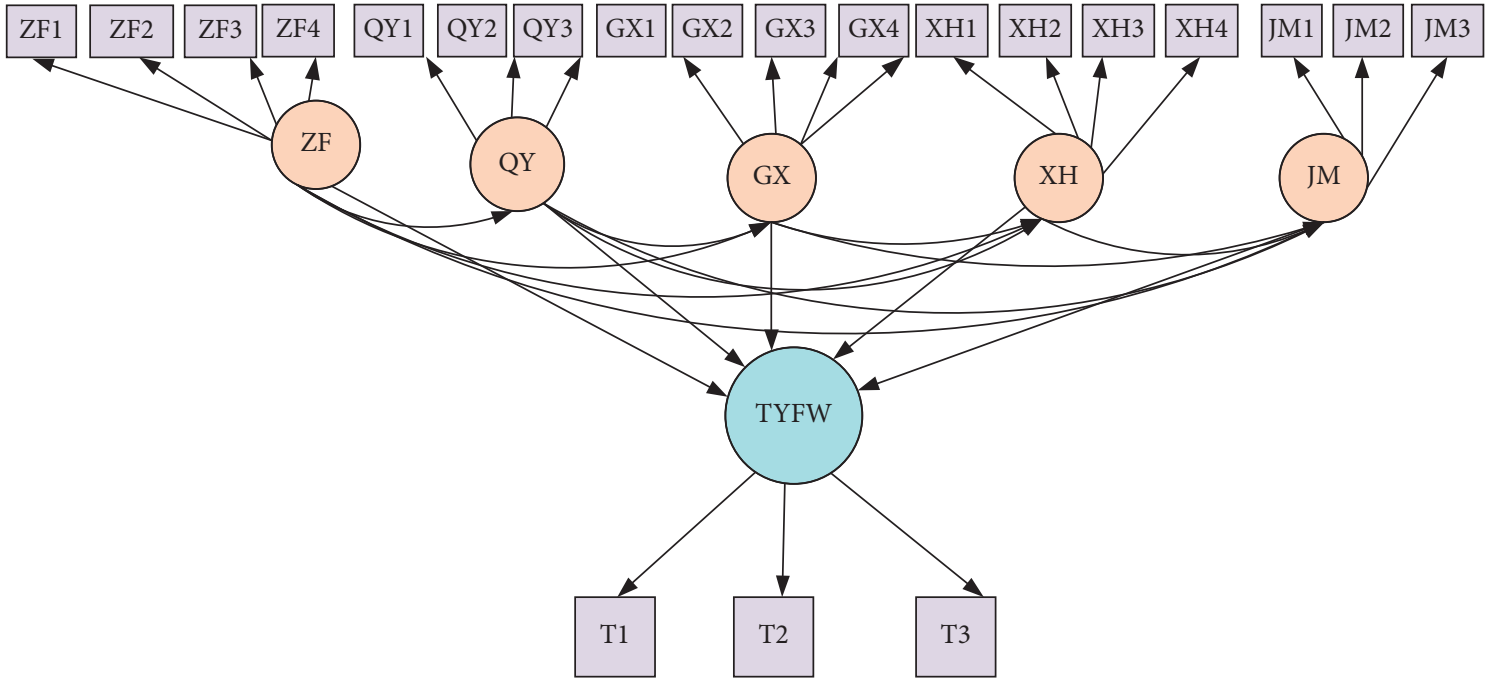

Figure 5: Direct relationship model.

The mediating effect model of the community environment is shown in Figure 6.

Figure 6 is used to test the hypothesis put forward in the previous part. The Bootstrap mediation effect test shows that the confidence intervals of the three mediation effects of government, community environment, sports service supply, colleges and universities, community environment, sports service supply, associations, community environment, and sports service attack all contain 0 . Therefore, there is no mediating effect, so the assumptions S1b, S3b, and S4b are not valid, and the assumptions S6a, S6c, and S6d are deleted. The mediation effect only considers the relationship between the community environment and the main body of supply and the supply of sports services.

The fit degree of Figures 5 and 6 is judged, and the result is shown in Figure 7.

Figure 7 shows that, in the direct relationship model and the mediation effect model, the 6 fitting indicators are consistent with the standard values, and no abnormal data appear. There is no mismatch in the indicators, and the data do not need to be revised. Therefore, the elements in the model are identified, and hypotheses that do not meet the requirements are deleted.

The standardized path coefficients and significance levels in the structural model are shown in Table 4.

The result of the hypothetical judgment in the mediation effect is as follows: the enterprise, community environment, and sports service supply are 0.29; the confidence interval does not include 0 ; the mediation effect value of residents, community environment, and sports service supply is 0.60 ; the confidence interval does not include 0. Hence, S6b and S6e are both established. In Figure 6, the standardized path coefficient of the enterprise to the community environment is 0.3 ; the path coefficient of the residents to the community environment is 0.06; the significant level is less than 0.001 , so, S2b and S5b are established.

Finally, the hypothesis test results are given, as shown in Table 5.
3.3. Analysis of Optimization Results of Networked Governance Model. The networked governance model is shown in Figure 8 .

Figure 8 suggests the following: (1) At present, the task of optimizing the networked governance model in the research area is to transform the leading role of the government and to give full play to the government's overall responsibility. Diversified and autonomous sports service supply is the current trend. In addition to the government, enterprises, universities, associations, and residents enter the field of sports services as important supplementary forces, which can solve the problem of the lack of professional talents in the government departments of the research area. (2) Supporting and cultivating social forces and maximizing the synergy can deal with the problem of insufficient sports services in the research area. The government should strictly access standards, cultivate social supply entities, and continuously optimize the supply structure of sports services in the research area. The division of powers and responsibilities in the market should give full play to the synergy of themes. (3) Supply links should be continuously improved, interaction between subjects should be continuously enhanced, and communication barriers should be broken. For example, the government achieves direct supply through policy guidance to sports service areas. Intermediate links between market entities should be reduced, supply efficiency should be improved, Internet resources should be effectively used, and complete efficient supply. (4) The role of the community environment should be maximized. S6b and S6e show that the community environment plays an intermediary role. This requires reasonable planning and simplification of the supply process in networked governance. (5) The main body should pay more attention to improving the communication mechanism. The degree of informatization should be improved, and the supply risk should be avoided in time. (6) The government plays a supervisory function and establishes an information security mechanism to provide guarantees for information security. The government should regulate the main access mechanism of the information system. (7) 


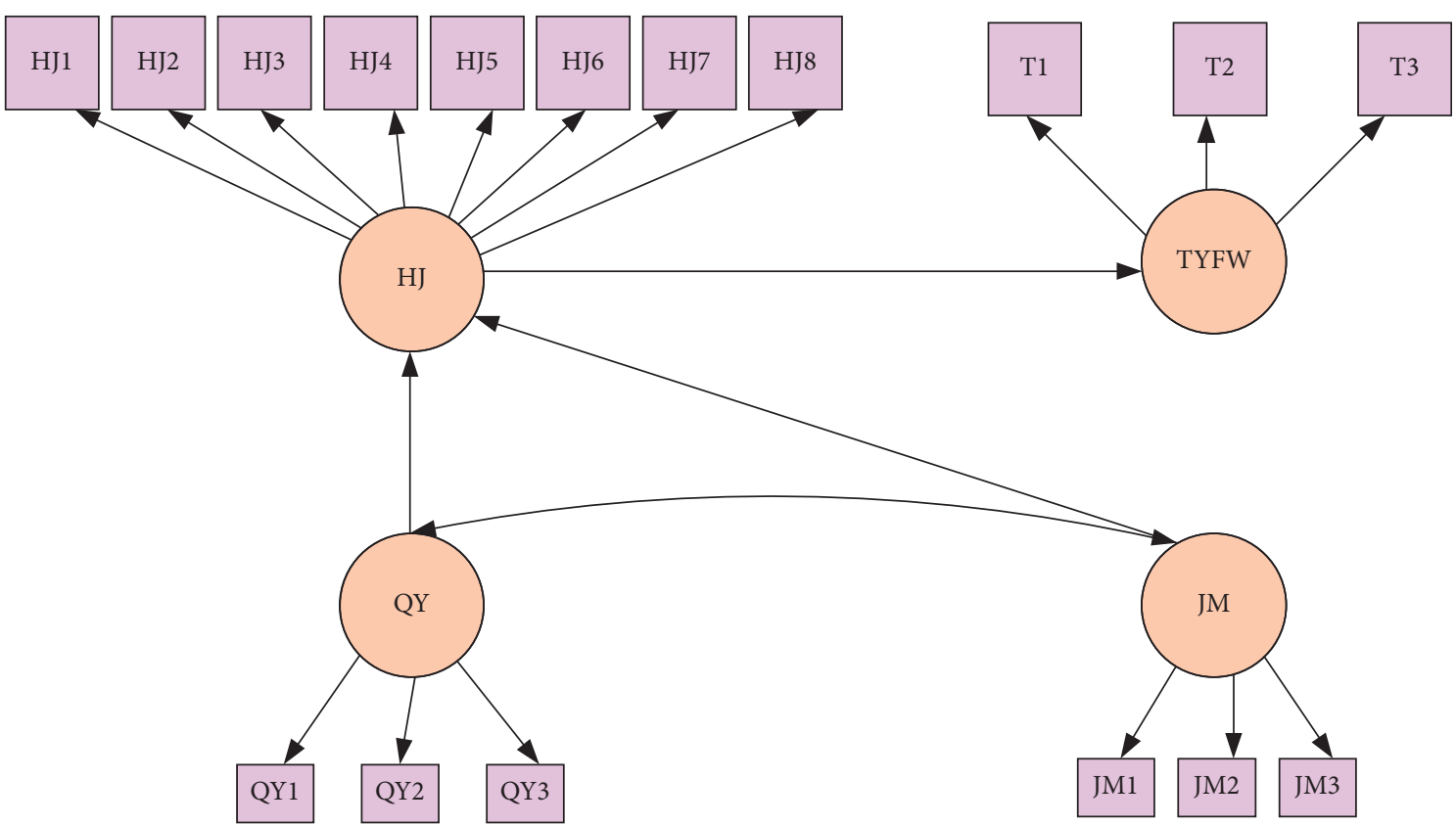

FIgure 6: The model of mediating effect.

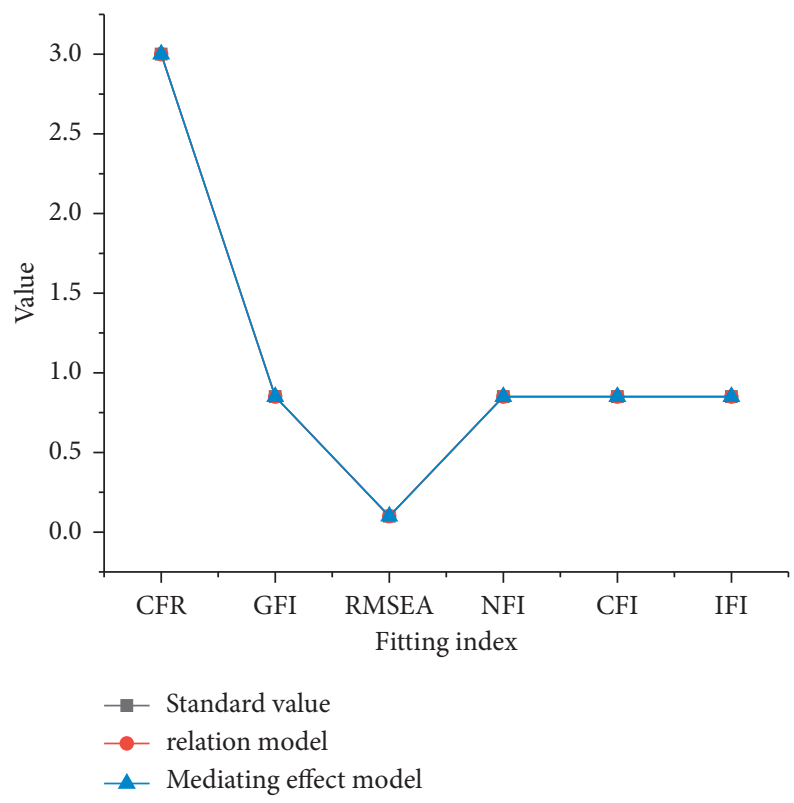

FIGURE 7: The test result of fitting index.

TABLE 4: Hypothetical judgments in the direct relationship.

\begin{tabular}{lccc}
\hline Supply body & Standardized path coefficient & Significant level & Hypothetical judgment \\
\hline Government & 0.56 & $<0.01$ & S1a established \\
Colleges & 0.16 & $<0.05$ & S3a established \\
Association & 0.08 & $<0.05$ & S4a established \\
Enterprise & -0.24 & $<0.05$ & S2a not established \\
Resident & -0.14 & $<0.05$ & S5a not established \\
\hline
\end{tabular}


TABLE 5: Hypothesis test results.

\begin{tabular}{|c|c|c|}
\hline $\begin{array}{l}\text { Hypothetical } \\
\text { number }\end{array}$ & The specific content of the hypothesis & Result \\
\hline S1a & Sports services are significantly affected by government entities & Established \\
\hline S2a & Sports services are significantly affected by the main body of the enterprise & $\begin{array}{l}\text { Not } \\
\text { established }\end{array}$ \\
\hline S3a & Sports services are significantly affected by the main body of colleges and universities & Established \\
\hline S4a & Sports services are significantly affected by the main body of the association & Established \\
\hline S5a & Sports services are significantly affected by residents & $\begin{array}{l}\text { Not } \\
\text { established }\end{array}$ \\
\hline S1b & The community environment is significantly affected by the government & Delete \\
\hline S2b & The community environment is significantly affected by business entities & Established \\
\hline $\mathrm{S} 3 \mathrm{~b}$ & The community environment is significantly affected by the main body of the university & Delete \\
\hline S4b & The community environment is significantly affected by the main body of the association & Delete \\
\hline S5b & The community environment is significantly affected by the residents & Established \\
\hline S6 & Sports services are significantly affected by the community environment & Established \\
\hline S6a & $\begin{array}{c}\text { The community environment plays an intermediary role between sports services and the supply of } \\
\text { government entities }\end{array}$ & $\begin{array}{l}\text { Not } \\
\text { established }\end{array}$ \\
\hline S6b & $\begin{array}{l}\text { The community environment plays an intermediary role between the sports service and the supply of } \\
\text { the main body of the enterprise }\end{array}$ & Established \\
\hline S6c & $\begin{array}{l}\text { The community environment plays an intermediary role between sports services and the supply of the } \\
\text { main body of colleges and universities }\end{array}$ & $\begin{array}{l}\text { Not } \\
\text { established }\end{array}$ \\
\hline S6d & $\begin{array}{l}\text { The community environment plays an intermediary role between the sports service and the supply of } \\
\text { the main body of the association }\end{array}$ & $\begin{array}{l}\text { Not } \\
\text { established }\end{array}$ \\
\hline S6e & $\begin{array}{c}\text { The community environment plays an intermediary role between sports services and the supply of } \\
\text { residents }\end{array}$ & Established \\
\hline
\end{tabular}

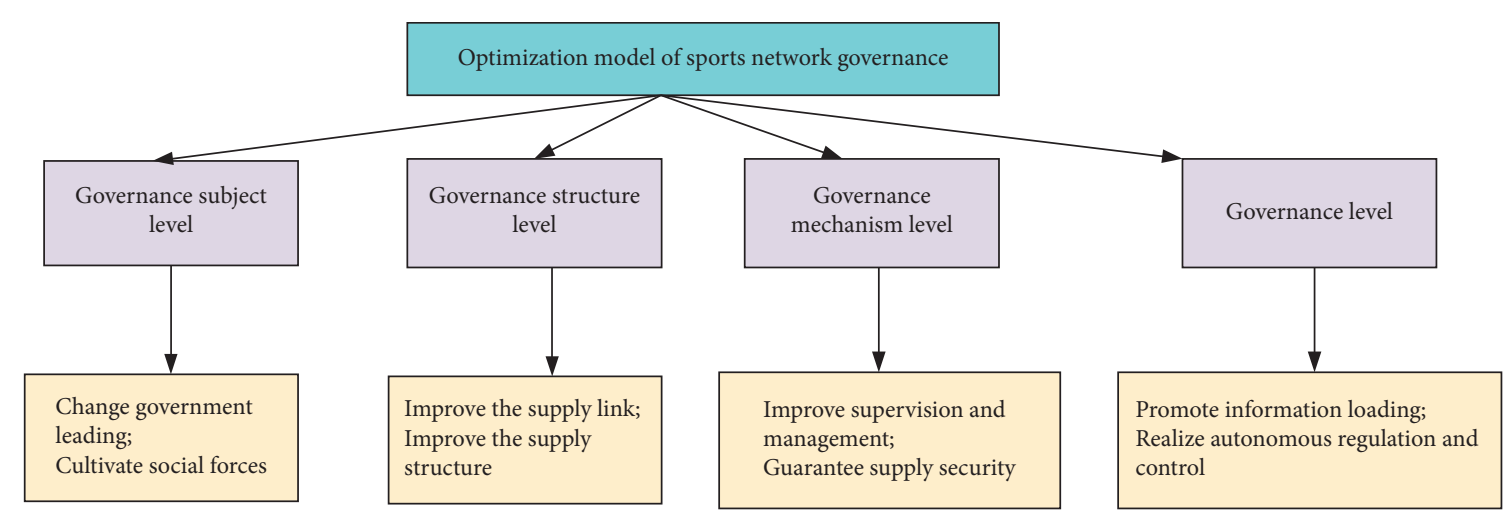

FIGURE 8: Optimization results of networked governance.

Information sharing tools should be used rationally, and information delivery systems should be established. (8) Network management should be promoted. Use networked management tools to connect the entire supply process and guide residents to actively participate in networked management.

\section{Conclusions}

Through the introduction of the background of networked governance, the supply strategy of sports services is analyzed. Since the supply problem, the networked governance model of the complex system under the sports service has been optimized. The results show that the government, universities, associations, and societies have a direct and positive impact on the supply of sports services. Enterprises and residents have little impact on the supply of sports services, but they have a positive effect on the community environment. The community environment promotes the supply of sports services and plays an intermediary role. Network governance should focus on the participation of multiple subjects, change the leading role of the government, break down the communication barriers between subjects, and establish an efficient communication mechanism and information sharing system. There are still deficiencies in the research. In determining the subject, due to the sample size, there may be other subjects that have not been taken into consideration. Subsequent research will analyze this part of the content in depth. Scientific governance is provided with a new possibility. The proposed networked governance model provides a greater space for autonomy in public sports services. It advocates the vigorous development of community nongovernmental organizations, stimulates the enthusiasm of community residents to participate, and 
ultimately promotes diversified network governance to achieve diversified participation and joint construction. The research provides a certain reference for the networked governance of sports services in the study area.

\section{Data Availability}

The data used to support the findings of this study are included within the article.

\section{Conflicts of Interest}

The authors declare that they have no conflicts of interest.

\section{Acknowledgments}

This study was supported by 2020 Annual Project of the 13th Five-Year Plan of Education Science in Guangdong Province, Research on multi-government cooperative governance model and mechanism innovation of sports events in Guangdong-Hong Kong-Macao Bay area (2020GXJK113).

\section{References}

[1] M. Alguacil, J. Núñez-Pomar, F. Calabuig, P. EscamillaFajardo, and I. Staskeviciute-Butiene, "Creation of a brand model through SEM to predict users' loyalty and recommendations regarding a public sports service," Heliyon, vol. 7, no. 6, Article ID e07163, 2021.

[2] P. Pinheiro and L. Cavique, "Regular sports services: dataset of demographic, frequency and service level agreement," Data in Brief, vol. 36, Article ID 107054, 2021.

[3] J. Garcia-Unanue, J. L. Felipe, L. Gallardo, C. Majano, and G. Perez-Lopez, "Decentralisation and efficiency in municipal sports services: expenditure vs. cost," Sustainability, vol. 13, no. 4, Article ID 2260, 2021.

[4] D. J. Jalolova, D. A. Xudaybyerdiyeva, and B. A. Abbosov, "The importance of marketing strategies in the provision of physical education and sports services," South Asian Journal of Marketing \& Management Research, vol. 10, no. 4, pp. 111-119, 2020.

[5] A. Mario, S. G. Javier, and V. Irena, "Be congruent and I will be loyal: the case of sport services," Sport in Society, vol. 23, no. 2, pp. 234-248, 2020.

[6] V. Demetris, V. Milena, S. Francesca, and M. Christofi, "Managing technological innovation in the sports industry: a challenge for retail management," Competitiveness Review: An International Business Journal, vol. 30, no. 1, pp. 78-100, 2019.

[7] A. Mario, N. P. Juan, P. C. Carlos, and V. Gascó, "Perceived value, satisfaction and future intentions in sport services: putting congruence and brand trust in the equation - linear models vs QCA," Academia. Revista Latinoamericana de Administración, vol. 32, no. 4, pp. 566-579, 2019.

[8] K. Kyungyeol, K. B. Kevin, B. Wooyeul, and A. Williams, "Examining structural relationships among sport service environments, excitement, consumer-to-consumer interaction, and consumer citizenship behaviors," International Journal of Hospitality Management, vol. 82, pp. 318-325, 2019.

[9] P. F. Katina, J. C. Pyne, C. B. Keating, and D. Komljenovic, "Complex system governance as a framework for asset management," Sustainability, vol. 13, no. 15, Article ID 8502, 2021.
[10] A. Mario, "Bottom-Up identification of subsystems in complex governance systems," Policy Studies Journal, vol. 48, no. 3, pp. 782-805, 2020.

[11] P. F. Katina and O. F. Keskin, "Complex system governance as a foundation for enhancing the cybersecurity of cyberphysical systems," International Journal of Cyber Warfare \& Terrorism, vol. 11, no. 3, pp. 1-14, 2021.

[12] B. K. Charles and P. F. Katina, "Complex system governance: concept, utility, and challenges," Systems Research and Behavioral Science, vol. 36, no. 5, pp. 687-705, 2019.

[13] T. Yuan, "Towards network governance: educational reforms and governance changes in China (1985-2020)," Asia Pacific Education Review, vol. 22, pp. 1-14, 2021.

[14] N. Zhao, Y. Liu, and J. Wang, "Network governance and the evolving urban regeneration policymaking in China: a case study of insurgent practices in enninglu redevelopment project," Sustainability, vol. 13, no. 4, p. 2280, 2021.

[15] J. H. Richard, C. Stephen, M. B. Joseph, and C. Keating, "Systems engineering and complex systems governance - lessons for better integration," INCOSE International Symposium, vol. 29, no. 1, pp. 421-433, 2019.

[16] W. Dave, "Leadership and foresight in complex system governance," International Journal of System of Systems Engineering, vol. 8, no. 3, pp. 249-267, 2018.

[17] N. H. Sweilam, D. Kumar, C. M. A. Pinto, and D. Baleanu, "Editorial note on the special issue: "fractional calculus models for the dynamics of complex systems," Journal of Advanced Research, vol. 32, pp. A1-A3, 2021.

[18] M. Grassia, M. De Domenico, and G. Mangioni, "Machine learning dismantling and early-warning signals of disintegration in complex systems," Nature Communications, vol. 12, no. 1, p. 5190, 2021.

[19] T. Go, B. F. Henrique, S. S. Roberto, and L. Basso, "Professional learning in physical education in Brazil: issues and challenges of a complex system," Sport, Education and Society, vol. 26, no. 7, pp. 773-787, 2021.

[20] N. Kapucu and Q. Hu, "The development of network governance and its relevance for public affairs education," Journal of Public Affairs Education, vol. 27, no. 3, pp. 267-275, 2021.

[21] A. H. Kabir, "Network governance' and the formation of the strategic plan in the higher education sector in Bangladesh," Journal of Education Policy, vol. 36, no. 4, pp. 1-25, 2021.

[22] M. Etemadi, P. Kenis, K. Ashtarian, H. Abolghasem Gorji, and H. Mohammadi Kangarani, "Network governance theory as basic pattern for promoting financial support system of the poor in Iranian health system," BMC Health Services Research, vol. 21, no. 1, p. 556, 2021.

[23] A. Matei, A.-S. Dumitru, and C.-G. Antonovici, "The EU health technology assessment and the open method of coordination: a relation with Potential in the context of network governance," Sustainability, vol. 13, no. 6, Article ID 3582, 2021.

[24] G. Giorgos and K. Ashok, "A dynamic model of global value network governance," Environment and Planning, vol. 53, no. 1, pp. 53-72, 2021.

[25] N. Kapucu and S. Beaudet, "Network governance for collective action in implementing united nations sustainable development goals," Administrative Sciences, vol. 10, no. 4, p. $100,2020$.

[26] O. Steven, V. Niels, M. Hugo, and B. Brugghemans, "Network of networks: preliminary lessons from the antwerp port authority on crisis management and network governance to deal with the COVID -19 pandemic," Public Administration Review, vol. 80, no. 5, pp. 880-894, 2020. 
[27] O. L. Larsson, "The governmentality of network governance: collaboration as a new facet of the liberal art of governing," Constellations, vol. 27, no. 1, pp. 111-126, 2020.

[28] D. Macdonald, R. Johnson, and B. Lingard, "Globalisation, neoliberalisation, and network governance: an international study of outsourcing in health and physical education," Discourse: Studies in the Cultural Politics of Education, vol. 41, no. 2, pp. 169-186, 2020.

[29] P. Oren, C. Reuven, and S. Nir, "Governance through global networks and corporate signalling," Regulation \& Governance, vol. 13, no. 4, pp. 447-469, 2019.

[30] T. Cragg, T. McNamara, I. Descubes, and F. Guerin, "Manufacturing SMEs, network governance and global supply chains," Journal of Small Business and Enterprise Development, vol. 27, no. 1, pp. 130-147, 2019. 